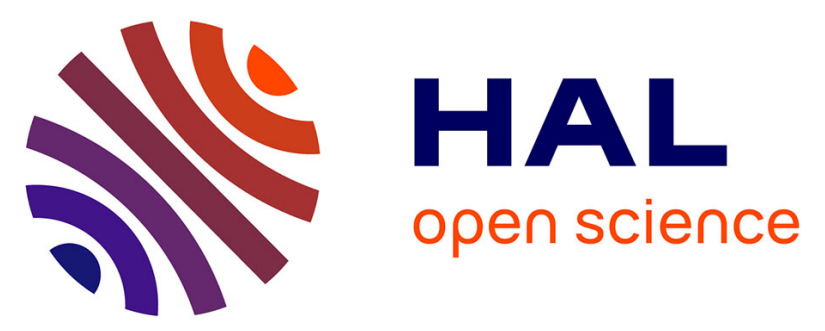

\title{
Reply to the comments of M.E. Golmakani and J. Rezatalab, Comment on "Nonlocal third-order shear deformation plate theory with application to bending and vibration of plates
}

Noël Challamel, J.N. Reddy

\section{To cite this version:}

Noël Challamel, J.N. Reddy. Reply to the comments of M.E. Golmakani and J. Rezatalab, Comment on "Nonlocal third-order shear deformation plate theory with application to bending and vibration of plates. Journal of Sound and Vibration, 2014, 333 (21), pp.5654-5656. 10.1016/j.jsv.2014.06.005 . hal-01113133

\section{HAL Id: hal-01113133 \\ https://hal.science/hal-01113133}

Submitted on 4 Feb 2019

HAL is a multi-disciplinary open access archive for the deposit and dissemination of scientific research documents, whether they are published or not. The documents may come from teaching and research institutions in France or abroad, or from public or private research centers.
L'archive ouverte pluridisciplinaire HAL, est destinée au dépôt et à la diffusion de documents scientifiques de niveau recherche, publiés ou non, émanant des établissements d'enseignement et de recherche français ou étrangers, des laboratoires publics ou privés. 


\title{
Reply to the comments of M.E. Golmakani and J. Rezatalab, Comment on "Nonlocal third-order shear deformation plate theory with application to bending and vibration of plates" (by R. Aghababaei and J.N. Reddy, Journal of Sound and Vibration 326 (2009) 277-289), Journal of Sound Vibration, 333 (2014) 3831-3835
}

\author{
Noël Challamel $^{\mathrm{a}, *}$, J.N. Reddy ${ }^{\mathrm{b}}$ \\ a Université Européenne de Bretagne, University of South Brittany UBS, UBS - LIMATB, Centre de Recherche, Rue de Saint Maudé, BP92116,
56321 Lorient cedex, France
${ }^{b}$ Department of Mechanical Engineering, Texas A\&M University, College Station, TX 77843-3123, United States
}

Golmakani and Rezatalab [1] suggested in their paper that the deflection of a simply supported nonlocal elastic plate under uniform load is not affected by the small length scale terms. They based their proof on the use of Navier's method using a sinusoidal-based deflection solution. This insensitivity of the deflection solution of a simply supported nonlocal elastic plate with respect to the small length terms of Eringen's model is not correct, as already detailed in the literature (for example, see [2] for beam problems). In fact, the deflection of the nonlocal plate (in the Eringen sense) is larger than the one of the local case, as shown in many papers available in the literature. We prove in this reply to the authors that the Navier's method has to be correctly applied for highlighting the specific sensitivity phenomenon of the deflection solution, as compared to exact analytical solution.

\section{The simply supported beam}

Let us consider the bending of a simply supported nonlocal Euler-Berrnoulli beam under uniformly distributed load. The Eringen's differential equation [3] is assumed for the bending-curvature constitutive law:

$$
M-l_{c}^{2} M^{\prime \prime}=E I w^{\prime \prime} \quad \text { and } \quad M^{\prime \prime}=q
$$

One recognizes in this case a nonlocal Euler-Bernoulli beam under a uniformly distributed load, whose analytical solution is given by Reddy and Pang [4], Wang et al. [5], and Zhang et al. [6]. The fourth-order differential equation of the

\footnotetext{
* Corresponding author.

E-mail addresses: noel.challamel@univ-ubs.fr (N. Challamel), jnreddy@tamu.edu (J.N. Reddy).
} 
bending problem of this nonlocal beam is given by

$$
E I w^{(4)}=q-l_{c}^{2} q^{\prime \prime}
$$

This fourth-order differential equation is not affected by the small length scale terms in case of uniform loading:

$$
q(x)=q_{0} \Rightarrow E I w^{(4)}=q
$$

whereas the boundary conditions of this simply supported problem are given, for the nonlocal beam, as

$$
w(0)=0, \quad M(0)=E I w^{\prime \prime}(0)+q l_{c}^{2}=0, \quad w(L)=0 \quad \text { and } \quad M(L)=E I w^{\prime \prime}(L)+q l_{c}^{2}=0
$$

leading to the solution ([4-6 or 7$])$ :

$$
w(x)=\frac{q}{E I}\left[\frac{x^{4}}{24}-\frac{x^{3} L}{12}+\frac{x L^{3}}{24}+\frac{l_{c}^{2} x}{2}(L-x)\right]=w_{0}(x)+\frac{q}{E I} \frac{l_{c}^{2} x}{2}(L-x) \geq w_{0}(x)
$$

The nonlocal term plays a softening effect, and the deflection of the nonlocal beam is larger than the one of the local problem, given by

$$
w_{0}(x)=\frac{q}{E I}\left[\frac{x^{4}}{24}-\frac{x^{3} L}{12}+\frac{x L^{3}}{24}\right]
$$

The softening behavior of the nonlocal approach with respect to the local one, has been recently confirmed for this bending problem by a microstructured discrete approach [7].

\section{Navier's solution}

Now, if we analyse this problem using the Navier's solution (see, for example [8]), we can expand the distributed load in trigonometric format:

$$
q(x)=\sum_{n=1}^{\infty} Q_{n} \sin \left(\frac{n \pi x}{L}\right)
$$

In the particular case of uniform loading $q(x)=q_{0}$, one calculates

$$
Q_{n}=\frac{2}{L} \int_{0}^{L} q_{0} \sin \left(\frac{n \pi x}{L}\right) d x=\frac{2 q_{0}}{n \pi}\left[1-(-1)^{n}\right]=\frac{4 q_{0}}{n \pi} \quad \text { for } n=1,3,5 \ldots
$$

It can be easily checked that

$$
\sum_{n=1}^{\infty} \frac{2 q_{0}}{n \pi}\left[1-(-1)^{n}\right] \sin \left(\frac{n \pi x}{L}\right)=q_{0}
$$

If now the deflection is assumed in a trigonometric series, as in the usual Navier's method

$$
w(x)=\sum_{n=1}^{\infty} W_{n} \sin \left(\frac{n \pi x}{L}\right)
$$

By replacing Eq. (10) in Eq. (3), and using Eq. (7), one obtains the series identity:

$$
\text { EI } \sum_{n=1}^{\infty} W_{n}\left(\frac{n \pi}{L}\right)^{4} \sin \left(\frac{n \pi x}{L}\right)=\sum_{n=1}^{\infty} Q_{n} \sin \left(\frac{n \pi x}{L}\right)
$$

One finally finds that the deflection of the nonlocal beam is not affected by the small length scale terms:

$$
w(x)=\sum_{n=1}^{\infty} \frac{Q_{n}}{E I}\left(\frac{L}{n \pi}\right)^{4} \sin \left(\frac{n \pi x}{L}\right)=w_{0}(x)
$$

However, in the case of uniform loading, it is wrong to set that

$$
q^{\prime \prime}(x)=-\sum_{n=1}^{\infty} Q_{n}\left(\frac{n \pi}{L}\right)^{2} \sin \left(\frac{n \pi x}{L}\right)=-\frac{2 q_{0}}{L^{2}} \sum_{n=1}^{\infty}\left[1-(-1)^{n}\right](n \pi) \sin \left(\frac{n \pi x}{L}\right)
$$

The reason is that $q^{\prime \prime}(x)=0$ if $q(x)=q_{0}$, whereas $\sum_{n=1}^{\infty}\left[1-(-1)^{n}\right](n \pi) \sin (n \pi x / L)$ is generally a divergent series. We are not allowed to make the derivation in the series term, because for the specific case $q(x)=q_{0}$, the sinusoidal-based series function which should be an odd function is then discontinuous at its boundaries. This discontinuous nature of the function in the Fourier series makes the simple derivation invalid as it is.

Clearly, following the reasoning presented in this part, the deflection should be unaffected by the small length terms of the nonlocal model, whereas the exact solution is of the nonlocal model Eq. (5) contains some length term effects.

The reason of this apparent paradox is due to the limit of validity of Navier's method for this problem. 


\section{A modified Navier's solution}

In fact, the deflection assumed in the form as in Eq. (10) cannot fulfill all the boundary conditions of the nonlocal problem given in Eq. (4). It means that it cannot constitute a complete basis for this problem.

Navier's solution implicitly assumed

$$
w^{\prime \prime}(0)=w^{\prime \prime}(L)=0
$$

whereas the nonlocal solution is based, for simply supported beams, on

$$
E I w^{\prime \prime}(0)=E I w^{\prime \prime}(L)=-q l_{c}^{2}
$$

It is well known that Navier's solution cannot be used for arbitrarily boundary conditions, and in the present problem, the static boundary conditions are clearly not fulfilled by the sinusoidal basis.

It is then recommended to use a modified version of Navier's solution. Integrating twice the unaffected fourth-order differential equation (Eq. (3)) leads to the following solution:

$$
\operatorname{EIw}^{\prime \prime}(x)=\frac{q x^{2}}{2}+A x+B
$$

where the constants $A$ and $B$ are identified from the static boundary conditions (Eq. (4)), thus leading to

$$
E I w^{\prime \prime}(x)=M(x)-l_{c}^{2} M^{\prime \prime}(x)=E I w_{0}^{\prime \prime}(x)-q l_{c}^{2}=\frac{q x^{2}}{2}-\frac{q L}{2} x-q l_{c}^{2}
$$

It is now possible to use the trigonometric basis expressed by Eq. (10) in the second-order differential equation (Eq. (17)):

$$
-\sum_{n=1}^{\infty} E I\left(\frac{n \pi}{L}\right)^{2} W_{n} \sin \left(\frac{n \pi x}{L}\right)=-\sum_{n=1}^{\infty} E I\left(\frac{n \pi}{L}\right)^{2} \frac{Q_{n}}{E I}\left(\frac{L}{n \pi}\right)^{4} \sin \left(\frac{n \pi x}{L}\right)-\sum_{n=1}^{\infty} Q_{n} l_{c}^{2} \sin \left(\frac{n \pi x}{L}\right)
$$

One finally finds

$$
W_{n}=\left[1+l_{c}^{2}\left(\frac{n \pi}{L}\right)^{2}\right] \frac{Q_{n}}{E I}\left(\frac{L}{n \pi}\right)^{4}
$$

We finally obtain the same equation as the one given by Eq. (5), where the small length terms appear to increase the local deflection:

$$
w(x)=\sum_{n=1}^{\infty}\left[1+l_{c}^{2}\left(\frac{n \pi}{L}\right)^{2}\right] \frac{Q_{n}}{E I}\left(\frac{L}{n \pi}\right)^{4} \sin \left(\frac{n \pi x}{L}\right) \geq w_{0}(x)
$$

Note that Eq. (20) would also be obtained by replacing the series expression Eq. (10) in Eq. (2) integrated two times.

In conclusions, the bending of simply supported nonlocal beams or nonlocal plates under uniform loading presents some scale effects. Navier's solution has to be correctly applied for capturing accurately these scale effects. Also, much of the discussion presented herein is equally valid for shear deformable beams and plates [9] and we will not elaborate the details here.

Note: Prior to the publication of the comment by Golmakani and Rezatalab [1], JSV did not contact the authors (Aghababaei and Reddy [9]) to seek their response. Only after reading the published comments, we have prepared this response.

\section{References}

[1] M.E. Golmakani, J. Rezatalab, Comment on Nonlocal third-order shear deformation plate theory with application to bending and vibration of plates (by R. Aghababaei and J.N. Reddy, Journal of Sound and Vibration 326 (2009) 277-289), Journal of Sound and Vibration 333 (2014) $3831-3835$.

[2] J.N. Reddy, Nonlocal theories for bending, buckling and vibration of beams, International Journal of Engineering Science 45 (2007) $288-307$.

[3] A.C. Eringen, On differential equations of nonlocal elasticity and solutions of screw dislocation and surface waves, Journal of Applied Physics 54 (1983) 4703-4710.

[4] J.N. Reddy, S.D. Pang, Nonlocal continuum theories of beams for the analysis of carbon nanotubes, Journal of Applied Physics 103 (2008) 023511.

[5] C.M. Wang, S. Kitipornchai, C.W. Lim, M. Eisenberger, Beam bending solutions based on nonlocal Timoshenko beam theory, Journal of Engineering Mechanics 134 (6) (2008) 475-481.

[6] Y.Y. Zhang, C.M. Wang, N. Challamel, Bending, buckling and vibration of hybrid nonlocal beams, Journal of Engineering Mechanics 136 (5) (2010) 562-574.

[7] N. Challamel, C.M. Wang, I. Elishakoff, Discrete systems behave as nonlocal structural elements: bending, buckling and vibration analysis, European Journal of Mechanics A/Solids 44 (2014) 125-135.

[8] J.N. Reddy, Theory and Analysis of Elastic Plates and Shells, 2nd Edition, Taylor and Francis, Philadelphia, 2007.

[9] R. Aghababaei, J.N. Reddy, Nonlocal third-order shear deformation plate theory with application to bending and vibration of plates, Journal of Sound and Vibration 326 (2009) 277-289. 